\title{
University faculty motivation to students' distant evaluation
}

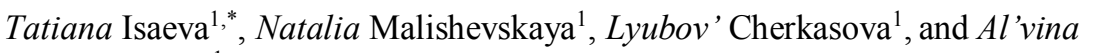 \\ Kolesnichenko ${ }^{1}$ \\ ${ }^{1}$ Rostov State Transport University, 2, Rostovskogo Strelkovogo Polka Narodnogo Opolcheniya Sq., \\ Rostov-on-Don, 344038, Russia
}

\begin{abstract}
During the period of remote learning in Russia, caused by measures to combat coronavirus infection in 2020, many university professors realized that dissatisfaction with the quality of their teaching activities, the teaching methods and the conditions in education was carried out, significantly reduced their motivation to teaching activity. The analysis of scientific literature showed that there is a lack of research on the motivation of university faculty, which is explained by the public attitude towards the initially high motivation of professors and the lack of methodological tools for conducting research. We used the following research methods: competence-based and system-activity approaches, as well as several theories of motivation developed by Russian and foreign scientists. Realizing that faculty motivation is one of the main factors that can ensure high quality education through the introduction of advanced teaching technologies, the article presents the results of an empirical study that made it possible to determine four main groups of negative factors that affect faculty motivation to carry out distant evaluation of the students. The recommendations are formulated for the university faculty, educational and methodological departments and administration of universities, which can contribute to the growth or maintenance of the faculty motivation both in "face-to-face" and distant educational process.
\end{abstract}

\section{Introduction}

During the period of remote learning in the universities of the Russian Federation, due to the need to take measures to prevent coronavirus infection, the faculty faced the task of evaluating the work of students in a distant mode. In connection with the changed conditions of teaching contacts, the professors had well-grounded fears about obtaining biased assessment results: to pass the test tasks, the students could use any reference resources, including Internet sites, with oral answers they also had the opportunity to extract material from textbooks and electronic devices, referring to the difficulties in establishing mobile communication and the lack of webcams, and having received traditional written homework assignments, many students expected their well-performing co-eds to complete them, and then sent copies of the corrected ones to the professors for checking.

Being in a stressful state due to the suddenness of a complete change in working

${ }^{*}$ Corresponding author: isaeva.te@yandex.ru 
conditions and the need to quickly master a variety of cloud platforms and information and communication technologies of education, university professors began to express dissatisfaction with the learning process as a whole, the results of their pedagogical work, and especially the available technologies for evaluating the students' knowledge and skills.

Considering the fact that in the 2020-2021 academic year the second "wave" of the COVID-19 pandemic may begin and higher educational institutions will again be forced to switch to remoted forms of contact with students, as well as the fact that, having received a generally positive experience of remoted learning, The Ministry of Science and Higher Education of the Russian Federation will fully expand the digitalization of higher education, there is a need to find ways to increase the motivation of faculty for remoted and mixed education, especially in the field of assessing the skills, abilities and competencies of the students.

The issues of motivation of the subjects of the educational process are regularly raised in scientific publications, however, they are considered somewhat one-sidedly in psychological and pedagogical literature: basically, scientific interest is concentrated on motivating students to various aspects of educational and cognitive activity $[1,2$, etc.]. With regard to the university professors, the most frequently considered questions are motivation of the students of teachers' training universities for future professional activities [3-4], working faculty - for professional development [5], for the implementation of professional duties $[6,7,9,10]$, etc. In recent years, in connection with the introduction of the category of educational managers in the academic environment, research has been carried out to identify the scope of their motivation [8]. However, studies on the motivation of university faculty to evaluate students remain extremely small despite the relevance of this scientific field.

The insufficient attention of researchers to the problem of studying the motivation of teachers, especially university professors, is indicated in the research by Martin Daumiller, Robert Stupnisky, Stefan Janke. Researchers emphasize the dominant role of faculty in the process of improving the quality of education, introducing innovative teaching methods and technologies and substantiate the following reasons for the insufficient degree of development of the aspect of motivation: the presence of an established stereotype that university teachers are initially motivated to their professional activities, as well as the lack of methodological and theoretical foundations for conducting research [9]. However, in recent years, a number of articles have appeared that consider various aspects of motivating university faculty to carry out various types of their professional activities: in the studies of Robert H. Stupnisky, Allison BrckaLorenz and their co-authors an attempt was made to identify the main factors that contribute to the maintenance and even growth of teachers' motivation to constantly improve their teaching activities [10]. According to a number of foreign researchers (J.A. Moreno-Murcia, Yo. Torregrosa, N.B. Pedreño) and the Russian scientist T.E. Isaeva [12], the motivation of professors must be taken into account in the process of developing criteria for assessing the competencies of university faculty [11, 12]. An example of this is the system for assessing the qualifications and competencies of faculty, used in Australia for a number of years [13].

In view of the fact that during the period of remote learning caused by the coronavirus pandemic, the emotional overload of university faculty has increased, complaints of emotional burnout and loss of interest in their activities have become more frequent, the issues of faculty motivating to conduct evaluation of the students, organized on the university territory, or in a distant mode have become especially relevant.

\section{Research methods and techniques}

To study the issues of faculty motivation to evaluate the work of students, the following aspects were used as a methodological basis: 
- a competence-based approach to teaching, on the basis of which a special evaluative competence of a teacher was revealed, which is a mandatory component of a teacher's pedagogical skill and includes five blocks: cognitive, technological, reflexive, developing and control-evaluative $[12,13$, etc.],

- system-activity approach, allowing to present the activity of a university professor in conducting distant evaluation of students as an interconnected process with their training, education and development $[1,2$, etc.],

- the theory of motivation, explaining the provision of opportunities for self-realization of a person in work on the basis of the model of "a creative person" by F. Herzberg, Theory of Needs by D. McClelland and the Expectancy Theory of Motivation by V. Vroom, as well as the social theory of motivation by A.G. Zdravomyslov.

Were also used psychodiagnostic tests, such as: test USK (level of subjective control of personality) (E.F. Bazhin, E.A. Golynkina, A.M. Etkind) [14], which is considered a modification of J. Rotter's scale (Rotter's Internal - External Control Scale), developed in 1966, "Motivation for Success and Fear of Failure" (A.A. Rean), "Teachers' Perceptions of Innovations" (T.S. Soloviov) to assess the level of achievements and readiness of university faculty to introduce innovative technologies [15].

\section{Results}

The issues of labor motivation are an object of interdisciplinary study, since every research in the field of pedagogy, psychology, sociology, economics, etc. reveals new facets in the formation of such a complex and contradictory phenomenon as motivation.

There are more than a dozen theories of motivation in modern science. In our study, we based on the theory of motivation as providing opportunities for self-realization of a person in work based on the model of "social" / "creative person" by F. Herzberg, Theory of Needs by D. McClelland and Expectancy Theory of Motivation by V. Vroom.

It is known that, according to the model of "social" / "creative person" by F. Herzberg, "hygienic factors" are distinguished, which include wages, social benefits, working conditions, employee status, enterprise climate, working atmosphere, environment, attitude to the boss and colleagues, etc., as well as "motivational factors": interesting work, an exciting work process, the ability to make independent decisions, a focus on achieving tangible results, recognition of achievements, the availability of a system of professional training and advanced training, etc. At the same time, F. Herzberg warned that without ensuring hygienic factors, the company's management should not proceed to creating motivational factors [17]. However, in the situation of the forced transition to remote learning, the lack of "hygienic factors" was clearly visible, due to the inconsistency of the technical electronic equipment used by the faculty at home with the complex tasks of network interaction, the working hours of professors have increased incomparably in relation to the traditional teaching load, their employment has become almost "round-the-clock", since asynchronous communication presupposes the availability of a teacher for contact almost all day long, at the same time, if wages have changed, then in the direction of reduction, since faculty have lost a number of incentive allowances and additional types of income. There were also no perceptible efforts on the part of the university administration to create "motivational factors", namely: the ability to make independent, in the opinion of faculty, more effective decisions on planning and implementing new technologies into the educational process was limited by unified administration decisions, individual achievements did not spread, as universities were focused on the implementation of "standard" requirements, naturally, there was no time and technical possibilities for organizing the system of advanced professional development that was so demanded at that time, many issues related to difficulties in using cloud platforms were resolved in informal chats of professors. 
The no less famous Theory of Needs by D. McClelland, which develops the classical "Pyramid of Needs" by A. Maslow, makes it possible for each person to satisfy three needs of the "highest level": power, success and belonging. Russian sociologist A.G. Zdravomyslov supplemented these needs with an interest in the content of a person's work, which is associated with the emergence of motives of an initiative, creative attitude to work, as well as an even higher group of motives in the hierarchy - public recognition of the importance of work, which is naturally associated with the fear of failure or negative opinion from the team [18]. The ideas of these theories were used by us in the course of an empirical study, the results of which will be demonstrated below.

The no less famous theory of D. McClelland, which develops the classical "pyramid of needs" by A. Maslow, makes it possible for each person to satisfy three needs of the "highest level": power, success and belonging. Russian sociologist A.G. Zdravomyslov supplemented these needs with an interest in the content of his work, which is associated with the emergence of motives of an initiative, creative attitude to work, as well as an even higher group of motives in the hierarchy - public recognition of the importance of work, which is naturally associated with the fear of failure or negative opinion from the team [18]. The positions of these theories were used by us in the course of an empirical study, the results of which will be demonstrated below.

In accordance with another theory of motivation - Expectancy Theory of Motivation by Victor Vroom [15], unlike other workers hoping for reward or recognition of the leadership, university faculty pinned their hopes on the higher efficiency of information and communication technologies (ICT ) in comparison with traditional ones, because this area of innovation in education is a priority today. When it turned out that the students were not completely satisfied with the learning outcomes, and the professors had accumulated a whole complex of objections and a wide list of shortcomings instead of satisfaction from the work performed, they began to reassure themselves that everything could be "made up" after returning to the "normal » form of education, re-examining the studied topics with students.

In scientific research, there are two approaches to the study of motivation, which, to some extent, complement each other: static (L. Bozhovich, K. Madsen, etc.), considering motivation as a set of constant motives aimed at achieving a certain goal, and dynamic (E.P. Ilyin [16], V. Yakhodnikova [15]). Considering the motivation of university faculty in the conditions of remote learning and taking into account the absence of a preparatory period on the transition to it, we assume that in this case we should focus on identifying dynamic motivation.

Usually, when researching the motivation of university professors to perform work functions, researchers pay attention to such factors as love for the profession, affection for students, dedication to their work, the academic staff of their university, duty to society, loyalty to pedagogical ideals and others $[9,10$, etc.].

The formation of motivation for teaching begins in the learning process at the teachers' training university $[3,4]$ and continues throughout the entire period of professional work of a faculty member. A separate area of study of ways to maintain motivation is the study of the problems of professional burnout of faculty associated with physical fatigue, constant stress, dissatisfaction with the results of their work, the attitude of students to the study of the taught discipline [7, 9, etc.], low social status, heavy workload (expressed in the number of classroom hours and additional types of work related to the performance of labor functions), which is expressed in insufficiently high wages, lack of additional measures of socio-economic, moral and financial incentives $[5,6$, etc. $]$

The issues of motivation of faculty acquire particular relevance during the periods of reforming of the education system, social upheavals and, as we witnessed in 2020, during "crisis situations".

As a result of a distance survey of 217 faculty members (the survey was conducted on the 
basis of a questionnaire developed by us in May-June 2020) teaching various academic disciplines and working at the Russian universities, the following groups of factors that negatively affect the motivation for distant evaluation were formulated:

- organizational and technical (lack of appropriate electronic devices, lack of a comfortable place to work with students, being busy "in front of the computer" most of the working day, etc.),

- psychological (emotional stress and overload, caused by malfunctions in the operation of technology, a change in the form of contact, lack of confidence in the presented results, etc.).

- methodological (expressing concerns about the lack of effectiveness of the lessons preceding the evaluation, the professors feared for the results of the testing, suggesting to transfer the control of knowledge to the next semesters)

- ethical (distrust in the organization of testing in a remote mode, when on another device students have the opportunity to open reference books, textbooks, etc., the lack of webcams among many students made the testing process for teachers "blind", since they only saw the black screen and received only test results).

Table 1 clearly reflects the opinion of the teachers about the negative factors accompanying the process of distance testing and reflected in the decrease in satisfaction with pedagogical activity, and, consequently, in motivation.

Table 1. Negative factors that manifested in the process of distant evaluation and influenced the decrease in the faculty motivation.

\begin{tabular}{|c|c|c|}
\hline Groups of factors & Type of factors & Number of answers \\
\hline $\begin{array}{l}\text { Organizational and } \\
\text { technical }\end{array}$ & $\begin{array}{l}\text { 1) Lack of appropriate electronic devices, } \\
\text { 2) lack of a comfortable place to work with } \\
\text { students, } \\
\text { 3) being busy "in front of the computer" most } \\
\text { of the working day. }\end{array}$ & $\begin{array}{l}65 \% \\
57 \% \\
84 \%\end{array}$ \\
\hline Psychological & $\begin{array}{l}\text { 1) Emotional stress and overload, stress, etc., } \\
\text { caused by equipment malfunctions, } \\
\text { 2) dissatisfaction with the change in the form } \\
\text { of contact, } \\
\text { 3) lack of confidence in the presented results } \\
\text { by the students, } \\
\text { 4) dissatisfaction with the results of their work. }\end{array}$ & $\begin{array}{l}72 \% \\
55 \% \\
62 \% \\
48 \%\end{array}$ \\
\hline Methodical & $\begin{array}{l}\text { 1) Lack of ICT skills, especially in the initial } \\
\text { period, } \\
\text { 2) lack of exercise to prepare for testing, } \\
\text { 3) unsatisfactory validity of test items. }\end{array}$ & $\begin{array}{l}55 \% \\
35 \% \\
42 \%\end{array}$ \\
\hline Ethical & $\begin{array}{l}\text { 1) Mistrust in the conditions of testing and the } \\
\text { honesty of students, } \\
\text { 2) Doubts about the effectiveness of the conducted } \\
\text { classes and the right to assess students on the basis } \\
\text { of distance learning. }\end{array}$ & $\begin{array}{l}64 \% \\
44 \%\end{array}$ \\
\hline
\end{tabular}

\section{Discussions}

The conducted research has confirmed our hypothesis about the need for constant organized activities to increase the motivation of teachers in the process of evaluating the work of students in conditions of remote learning.

Based on the identified by us structure of the evaluation competence of a university 
professor $[12,13]$, we suggest that this work be carried out in the following modes:

a) as a teacher - at the individual level,

b) the educational and methodological management of the university - at the level of "parity relations",

c) at the level of the university administration - at the level of management of the activities of employees.

Educational and methodological management, in turn, should take care of creating normal conditions for professors who teach remotely. It is clear that when Russian universities at the end of March 2020 were forced to switch to remote forms of pedagogical contacts, the process of organizing technical access to electronic knowledge bases, the University's Electronic Information-and-Educational Environment, cloud platforms for educational interaction, as well as faculty's self-training to use them took place spontaneously, in a disorganized way, with a certain delay from the arising daily tasks. However, now, when the faculty have a certain reserve of time, and most importantly, they have accumulated valuable experience, it is necessary to make significant additions to the technical equipment of these procedures.

We fully agree with the position of N. Efremova, S. Shvedova and F. Khuseynova that the fundamental requirement for any evaluation process should be accessibility, openness, transparency, visibility of assessment results, which should be quantified and used not as a means of punishing of the students, but as, in turn, a tool for their motivation [1, p.2]. In most cases, students during the period of remote learning could immediately see the results of their testing in their private offices if it was carried out by specialized structural divisions of universities. However, in the conditions of synchronous and asynchronous teaching in disciplines, the results of the current control and assessment of knowledge in many cases were inaccessible to students. The teacher could report them separately to each student in individual chats, or s/he could put marks in his / her personal register, since the electronic registers are not equipped with the function of putting marks. Not seeing their results or not being able to compare their progress with the marks of their peers in the group, students often lost interest in the learning process and were guided only by the final test or exam. As a result, the professor, faced with a deterioration in the attendance of classes in the distant mode or not receiving completed assignments from students for a long time, felt dissatisfaction with the results of his/her work. $100 \%$ of the surveyed university professors point to the feeling of "a lot of time and effort spent on preparing for remote learning, and students do not get in touch for months, do not send their homework, shamelessly write off information from the Internet".

Educational and methodological management, in turn, should take care of creating normal conditions for professors who teach remotely. It is clear that when Russian universities at the end of March 2020 were forced to switch to remote forms of pedagogical contacts, the process of organizing technical access to electronic knowledge bases, the University's Electronic Information-and-Educational Environment, cloud platforms for educational interaction, as well as faculty's self-training to use them took place spontaneously, in a disorganized way, with a certain delay from the arising daily tasks. However, now, when the faculty have a certain reserve of time, and most importantly, they have accumulated valuable experience, it is necessary to make significant additions to the technical equipment of these procedures.

We fully agree with the position of N. Efremova, S. Shvedova and F. Khuseynova that the fundamental requirement for any evaluation process should be accessibility, openness, transparency, visibility of assessment results, which should be quantified and used not as a means of punishing of the students, but as, in turn, a tool for their motivation [1, p.2]. In most cases, students during the period of remote learning could immediately see the results of their testing in their private offices if it was carried out by specialized structural divisions of 
universities. However, in the conditions of synchronous and asynchronous teaching in disciplines, the results of the current control and assessment of knowledge in many cases were inaccessible to students. The teacher could report them separately to each student in individual chats, or s/he could put marks in his / her personal register, since the electronic registers are not equipped with the function of putting marks. Not seeing their results or not being able to compare their progress with the marks of their peers in the group, students often lost interest in the learning process and were guided only by the final test or exam. As a result, the professor, faced with a deterioration in the attendance of classes in the distant mode or not receiving completed assignments from students for a long time, felt dissatisfaction with the results of his/her work. $100 \%$ of the surveyed university professors point to the feeling of "a lot of time and effort spent on preparing for remote learning, and students do not get in touch for months, do not send their homework, shamelessly write off information from the Internet".

\section{Conclusions}

The motivation of a university professor in the process of distant evaluation of the students can be formed if the following conditions are met:

- a clear organization of the process of combining face-to-face / contact and distant classes, which implies a greater share of pedagogical interaction in the traditional mode and the transfer of no more than $25 \%$ of academic time to remote forms of interaction,

- availability of reliable technical, electronic support for remote classes, the organization of specialized classrooms on the territory of the university, provided that the teacher is not able to conduct such classes from home,

- development and approval at the university (and, possibly, on the federal level) of the procedure for pedagogical interaction between professors and students in the conditions of distant / mixed / complementary education. The latter term was introduced by us and implies, by complementary training, the voluntary use by professor of remote forms of interaction with students extra to working hours in order to save classroom time, expand the range of teaching aids through network resources, and additional consultation using proven digital technologies. Such a procedure should include organizational and legal issues of education, a description of the methodological, information and communication resources offered to the faculty and students, prospects for improving the qualifications of the faculty in the field of ICT, aspects of pedagogical ethics and behavior during remote sessions, as well as forms of promotion of best practices and encouragement of the most effective professors in the field of distance learning.

- availability of a reliable procedure for current and final control, both in terms of content and forms of organization and demonstration of the results of academic performance of individual students, student groups and streams, which will enable professors to visualize the results of mastering their disciplines and use data to improve learning,

- the use of the results of evaluation of students in a comprehensive assessment of the professor's activities in the course of the competitive selection procedure, appointment to a position, etc.,

- introduction of specialized courses to develop the qualifications of faculty in the field of assessment of students, where they can acquire knowledge about modern approaches to assessment, evaluation functions in personality development, technical skills for conducting remote evaluation and other issues.

Summarizing the above, it should be noted that despite the fact that educational, methodological and administrative bodies are assigned a significant role in increasing the motivation of university teachers, the professors should be aware of themselves as managers of a new form of learning organization, since, having received valuable experience in using 
electronic resources and ICT during the period of remote learning, they will no longer be able to teach "in the old way", but will constantly seek forms of introducing new digital technologies into the learning process. Therefore, they should think about and independently determine the goals, meanings, technologies of their activities and be guided by the principle "developing myself, I contribute to the development of students", which will become the main factor in creating pedagogical motivation.

\section{References}

1. N. Efremova, S. Shvedova, F. Huseynova, Trends in the Development of PsychoPedagogical Education in the Conditions of Transitional Society (ICTDPP-2019). SHS Web Conf. 70, 04003 (2019) DOI: https://doi.org/10.1051/shsconf/20197004003

2. S. Baluyan, Trends in the Development of Psycho-Pedagogical Education in the Conditions of Transitional Society (ICTDPP-2019). SHS Web Conf. 70, 04002 (2019) DOI: https://doi.org/10.1051/shsconf/20197004002.

3. M.T. Khadzhiev, B.Kh. Rakhimov, ARPHA Proceedings 1: V International Forum on Teacher Education: Part I: Teacher Education and Training (2019) DOI: 10.3897/ap.1.e0307

4. A.S. Yeung, E. Tay, C. Hui, J. H. Lin, E. Low, Australian Journal of Teacher Education 39(3) (2014) http://dx.doi.org/10.14221/ajte.2014v39n3.1

5. T. Isaeva, M. Kaplyuk, Revista Espacios 39(43), 32-43 (2018) http://www.revistaespacios.com/a18v39n43/a18v39n43p32.pdf

6. T. Isaeva, M.P. Chourikov, Yu.Yu. Kotlyarenko, Modern European Researches Salzburg, Austria 4, 32-40 (2015) https://doaj.net/uploads/issue/issue_8.pdf

7. T. Isaeva, Proceedings of 17-th International Scientific and Practical Conference "Teacher of a Higher School in the 21-st Century" (Rostov State Transport University, Rostov-on-Don, 2020) http://t21.rgups.ru/upload/files/Sbornik_2020.pdf

8. T. Shcherbakova, D. Misirov, V. Kirik, I. Loseva, Trends in the Development of PsychoPedagogical Education in the Conditions of Transitional Society (ICTDPP-2019). SHS Web Conf. 70, 05008 (2019) DOI: https://doi.org/10.1051/shsconf/20197005008

9. M. Daumiller, R. Stupnisky, S. Janke, et al, International Journal of Educational Research 99, 101502 (2020) https://doi.org/10.1016/j.ijer.2019.101502

10. R.H. Stupnisky, et al., Contemporary Educational Psychology 53, 15-26 (2018) https://doi.org/10.1016/j.cedpsych.2018.01.004

11. J.A. Moreno-Murcia, Yo.S. Torregrosa, N.B. Pedreño, New approaches in educational research 4(1), 54-61 (2015) DOI: 10.7821/naer.2015.1.106.

12. T.E. Isaeva, Higher Education in Russia 10, 106-112 (2014) https://www.elibrary.ru/download/elibrary_22536479_40021188.pdf

13. Training and Assessment Qualifications and Competencies (Site of Federation University, Australia) http://policy.ballarat.edu.au/ tafe/teacher_qualifications_competence/ch01.php

14. E.F. Bazhin, E.A. Golynkina, A.M. Etkind, Diagnostics of the level of subjective control https://studme.org/202410/psihologiya/diagnostika_urovnya_subektivnogo_kontrolya_ bazhin_golynkina_etkind

15. V. Yahodnikova, Science and Education: Psychology 11, 139-145 (2017) DOI: https://doi.org/10.24195/2414-4665-2017-11-18

16. E.P. Ylyn, Motivation and motivation (Saint Petersburg, 2000) 
https://psy.wikireading.ru/65088

17. F. Herzberg, B. Mausner, B. Snyderman, The motivation to Work (N.Y., 1959) https://pdf.wecabrio.com/motivation-to-work-frederick-herzberg-1959-pdf-free.pdf

18. A.G. Zdravomyslov, Requirements, interests, values (Moscow, 1986) https://www.studmed.ru/zdravomyslov-a-g-potrebnosti-interesycennosti_d444f37cce2.html 